\title{
The molecular structure ordering and orientation of the metallophthalocyanine CoPc, ZnPc, CuPc, and MgPc thin layers deposited on silicon substrate, as studied by micro-Raman spectroscopy
}

\author{
M. Szybowicz $\cdot$ W. Bała $\cdot$ K. Fabisiak $\cdot$ \\ K. Paprocki $\cdot$ M. Drozdowski
}

Received: 10 March 2011 / Accepted: 3 May 2011/Published online: 12 May 2011

(C) The Author(s) 2011. This article is published with open access at Springerlink.com

\begin{abstract}
In this article, we present orientation study of metallophthalocyanine (MPcs) (CoPc, $\mathrm{ZnPc}, \mathrm{CuPc}$, and $\mathrm{MgPc}$ ) thin films deposited on silicon substrate. The MPc's thin layers were obtained by the quasi-molecular beam evaporation. The micro-Raman scattering spectra of MPc's thin films were investigated in the spectral range $550-1650 \mathrm{~cm}^{-1}$ using $488 \mathrm{~nm}$ excitation wavelength. Raman scattering studies were performed at room temperature before and after annealing process. Annealing process of thin layers was carried out at $200{ }^{\circ} \mathrm{C}$ for $6 \mathrm{~h}$. From polarized Raman spectra using surface Raman mapping, the information on polymorphic phase of MPc's layers has been obtained. The chosen Raman modes $\mathrm{A}_{1 \mathrm{~g}}$ and $\mathrm{B}_{1 \mathrm{~g}}$ are connected with different polymorphic phases of MPc ( $\alpha$ and $\beta$ form) thin layers. Moreover, the obtained results showed the influence of the annealing process on the ordering of the molecular structure. Following the annealing process, it was observed arrangement of the thin layers structure being revealed in Raman spectra. The obtained results indicate that the annealing process has a significant influence on the structure of thin layers being under study.
\end{abstract}

\footnotetext{
M. Szybowicz $(\varangle) \cdot$ M. Drozdowski

Faculty of Technical Physics, Poznan University of Technology,

Nieszawska 13A, 60-965 Poznań, Poland

e-mail: miroslaw.szybowicz@put.poznan.pl

W. Bała $\cdot$ K. Fabisiak $\cdot$ K. Paprocki

Institute of Physics, Kazimierz Wielki University, Weyssenhoff

Sq. 1, 85-072 Bydgoszcz, Poland
}

\section{Introduction}

In recent years, the organic thin layers play an important role in finding new materials for optoelectronic applications and devices. One of them are the thin layers of organic compound based on metallophthalocyanine (MPc) ( $\mathrm{CoPc}, \mathrm{ZnPc}, \mathrm{CuPc}$, and $\mathrm{MgPc}$ ) deposited on a solid state substrate using different methods (quasi-molecular beam evaporation, Langmuir-Blodgett, evaporation from solution, and spin-coating method). The MPc are the most promising materials for future molecular devices such as organic light emitting diodes (OLEDs), solar cells, organic field-effect transistors, molecular gas sensors, memories, optoelectronic device, and semiconductor junctions [1-5]. Metallophthalocyanines represent a large family of heterocyclic conjugated molecules with high chemical and thermal stability $[6,7]$.

During last years, the thin films of phthalocyanines MPc with different central metal atoms $(\mathrm{CoPc}, \mathrm{ZnPc}, \mathrm{CuPc}$, and $\mathrm{MgPc}$ ) have been extensively studied due to their potential properties as electronic or optoelectronic materials, gas sensor, and possible application for fabrication of functional low dimensional structures on solid surfaces. In the case of MPc thin films, the knowledge of the surface morphology and the preferred orientation of the crystallites are essential for their successful applications. Within the analysis of preferred orientation of molecules in MPc's layers, polymorphism of crystalline structure MPc's layer plays an important role and is related to their physical properties (optical and electrical) [7, 8].

Metallophthalocyanines can occur in many polymorphic phases $\alpha, \beta, \chi$, and $\varepsilon$ connected with different crystalline structure. The most popular is metastable $\alpha$ form and stable $\beta$ form $[9,10]$. The main difference between both forms is the tilt angle of the molecule within the columns and 
arrangement of the common columns in the crystalline structure. These parameters play a significant role in changes of conductivity along stacking molecules. Thus, the obtained thin layers possessing different phases of MPc molecules lead to different optical and electrical properties. Therefore, during the deposition process (using the different substrates and deposition methods) one can obtain different heterogeneous polymorphic phase of MPc thin layer.

Due to these exceptional properties, thin films of MPcs have been recently intensively investigated using the optical methods such as absorption ellipsometry, FTIR absorption, Raman spectroscopy, X-ray diffraction, scanning electron microscopy, and atomic force microscopy [11-16]. The preferred orientation is usually determined by sample preparation conditions such as the type of substrate (amorphous or single crystalline), type of deposited layer (different organic materials), temperature of substrate, deposition rate, quality of the substrate surface, and method of deposition.

Also the annealing processes of organic thin layers after deposition on substrate are very important because in many cases they can lead to changes in polymorphic forms and arrangement of the structure $[16,17]$.

The influence of different deposition conditions on both, the preferred orientation of MPc's crystallites within films and on the surface morphology were investigated using different methods $[15,18]$. In the investigations, we used the orientation dependencies of polarized Raman spectra. The main aim of this study was to determine the molecular orientation and distribution of polymorphic phase of MPc thin film deposited on silicon substrate and to identify changes occurring as a result of annealing process.

\section{Experimental}

Thin film preparation

The MPc (CoPc, $\mathrm{ZnPc}, \mathrm{CuPc}$, and $\mathrm{MgPc})$ layers have been prepared in vacuum chamber at pressure of about $p=2 \times 10^{-4} \mathrm{~Pa}$. Purified CoPc, ZnPc, CuPc, and MgPc powder (97\% Sigma-Aldrich Co.) was loaded onto a quartz effusion cell with a nozzle of $3 \mathrm{~mm}$ in diameter on the top. The n-type (001) Si substrates were located $10 \mathrm{~cm}$ away from the source of MPc which before loaded into vacuum chamber were sonificated in acetone, distilled water, isopropanol, and finally in distilled water. During evaporation the substrates were held at room temperature. The deposition rate was $0.2 \mathrm{~nm} / \mathrm{s}$. We obtained thin layers $\mathrm{CoPc}, \mathrm{ZnPc}, \mathrm{CuPc}$, and $\mathrm{MgPc}$ about the thickness of $400 \mathrm{~nm}$.
Characterization of thin films

The Raman scattering spectra of MPc's layers were investigated in the spectral range of $550-1650 \mathrm{~cm}^{-1}$. The nonpolarized and two type of polarized ( $\mathrm{VV}$ and $\mathrm{VH})$ Raman spectra were recorded in the backscattering geometry using inVia Renishaw micro-Raman system. As an excitation light we used the blue line of argon laser operating at $488 \mathrm{~nm}$. The same laser as a source of exciting light was used to study Raman surface mapping. The laser beam was tightly focused on the sample surface through a Leica 50× LWD microscope objective (LWD—long working distance) with numerical aperture equal to 0.5 leading to a laser beam diameter about $2 \mu \mathrm{m}$. To determine orientation of the MPc's thin layer the polarized (VV and VH) Raman spectra were recorded. To prevent any damages of the sample an excitation power was fixed at $5 \mathrm{~mW}$. The inVia Raman spectrometer allowed for recording the Raman spectra with the spatial resolution of about $1 \mu \mathrm{m}$. Because all measurements were recorded in backscattering geometry we could neglect the angle dependence of reflection coefficients of thin layer and substrate for different polarization of the incident light. The position of the microscope objective with respect to the thin layer was piezoelectrically controlled during surface mapping ( $X Y$ position). The reference position (level 0 ) was assumed for the laser spot focused on the surface of sample. The obtained Raman maps of surface of the thin layer covered an area $20 \times 20 \mu \mathrm{m}$ with the step of $2 \mu \mathrm{m}$.

\section{Results and discussion}

The determination of molecular orientation of thin layer from Raman scattering studies was based on the analysis of external molecular vibrations. The molecular orientation of thin film is connected with the elements of matrix of scattering tensors for individual type of vibrations.

In order to obtain information on the components of Raman tensor for appropriate type of vibration the diagonal and nondiagonal elements of the Raman tensor have been determined. Determination of these elements was performed using polarized Raman spectra, VV-in parallel polarization of incident and scattered light and $\mathrm{VH}-$ in cross polarization of incident and scattered light.

The vibrations of the $\mathrm{CoPc}, \mathrm{ZnPc}, \mathrm{CuPc}$, and $\mathrm{MgPc}$ planar molecules which consist of 57 atoms and possess $\mathrm{D}_{4 \mathrm{~h}}$ point group symmetry can be classified into following irreducible representation (taking into account only internal vibrations) [19, 20]:

$$
\begin{aligned}
\Gamma_{\text {vib }}= & 14 \mathrm{~A}_{1 \mathrm{~g}}+13 \mathrm{~A}_{2 \mathrm{~g}}+14 \mathrm{~B}_{1 \mathrm{~g}}+14 \mathrm{~B}_{2 \mathrm{~g}}+13 \mathrm{E}_{\mathrm{g}} \\
& +6 \mathrm{~A}_{1 \mathrm{u}}+8 \mathrm{~A}_{2 \mathrm{u}}+7 \mathrm{~B}_{1 \mathrm{u}}+7 \mathrm{~B}_{2 \mathrm{u}}+28 \mathrm{E}_{\mathrm{u}}
\end{aligned}
$$


where $A_{1 g}, B_{1 g}, B_{2 g}$, and $E_{g}$ modes are Raman-active. The nondegenerate $A_{1 g}, B_{1 g}$, and $B_{2 g}$ modes are in-plane vibrations, and double degenerate $\mathrm{E}_{\mathrm{g}}$ are the out-of-plane vibrations. In the case of symmetry $\mathrm{D}_{4 \mathrm{~h}}$, the Raman tensors for each modes Raman-active $\left(\mathrm{A}_{1 \mathrm{~g}}, \mathrm{~B}_{2 \mathrm{~g}}\right.$, and $\left.\mathrm{E}_{\mathrm{g}}\right)$ can be described [19, 21].

As it is known the Raman intensities of the bands are proportional to the square of matrix elements. Thus, average intensity of the band in parallel polarization incident and scattered light (VV) and in cross polarization incident and scattered light $(\mathrm{VH})$ is described by following formulas [20]:

$$
\begin{aligned}
& I_{\mathrm{VV}}=\frac{2}{\pi} \int_{0}^{\pi / 2} k^{2} \cos ^{4} \beta \mathrm{d} \phi=k^{2} \cos ^{4} \beta, \\
& I_{\mathrm{VH}}=\frac{2}{\pi} \int_{0}^{\pi / 2} k^{2} \sin ^{2} \phi \cos ^{2} \beta \sin ^{2} \beta \mathrm{d} \phi=\frac{k^{2}}{2} \cos ^{2} \beta \sin ^{2} \beta,
\end{aligned}
$$

where $\beta$ is the angle between molecule and substrate. The $\beta$ angle is calculated from the ratio intensities $\left(I_{\mathrm{VV}} / I_{\mathrm{VH}}\right)$ for
$\mathrm{A}_{1 \mathrm{~g}}$ and $\mathrm{B}_{1 \mathrm{~g}}$ Raman modes of MPcs deposited on solid state substrate. Detailed informations concerning the designation of the orientation of the MPc thin layers using polarized Raman spectra we concluded in the previous works [21, 22].

The orientation of MPc's thin layers is closely connected with parameters of the deposition process such as: temperature of the substrate, deposition rate, method of evaporation, and thickness of the obtained thin layers. Annealing process of the obtained thin films also plays a very important role, which can cause transformation of molecular structure and change of polymorphic phase. This leads to the structure arrangement and ordering of thin layer.

Figure 1 presents the polarized Raman spectra (VV and VH) obtained at room temperature (before annealing procedure) for $\mathrm{ZnPc} / \mathrm{Si}$ (a), $\mathrm{CuPc} / \mathrm{Si}$ (b), $\mathrm{CoPc} / \mathrm{Si}(\mathrm{c}), \mathrm{MgPc} / \mathrm{Si}$ (d), respectively. As it is shown in Fig. 1 we recoded bands of $A_{1 \mathrm{~g}}$ symmetry of $592 \mathrm{~cm}^{-1}$ band (benzene ring deformation), $\mathrm{B}_{1 \mathrm{~g}}$ at $684 \mathrm{~cm}^{-1}$ (macrocycle breathing), and $\mathrm{B}_{1 \mathrm{~g}}$ connected with pyrrole stretch. The position of the last band is closely linked to metal ion adapted to phthalocyanine molecule. The major changes in Raman spectra for different MPc thin layers are observed in the spectral range
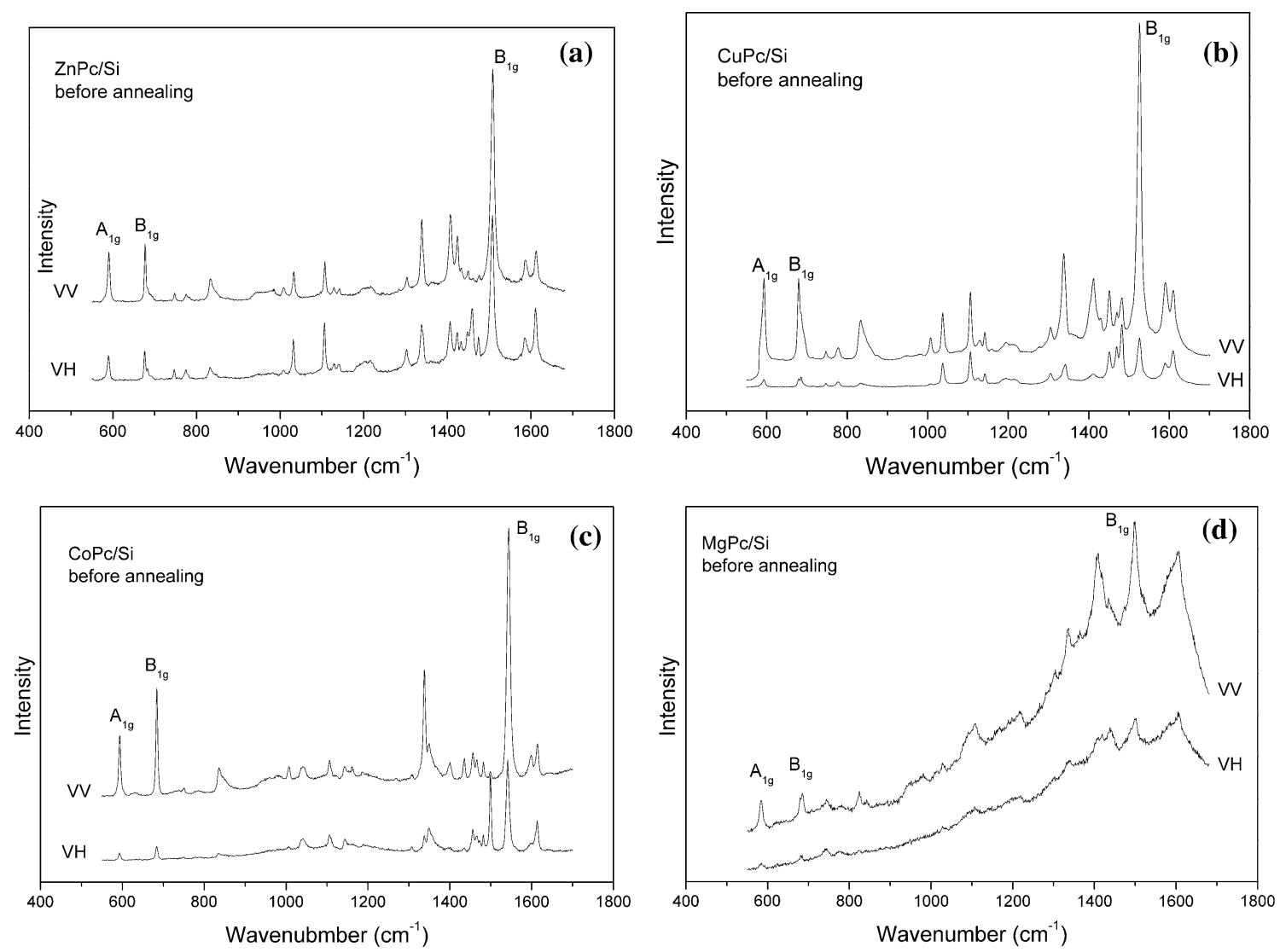

Fig. 1 Polarized Raman spectra MPc deposited on silicon substrate: $\mathrm{ZnPc}(\mathbf{a}), \mathrm{CuPc}(\mathbf{b}), \mathrm{CoPc}(\mathbf{c}), \mathrm{MgPc}(\mathbf{d})$ 


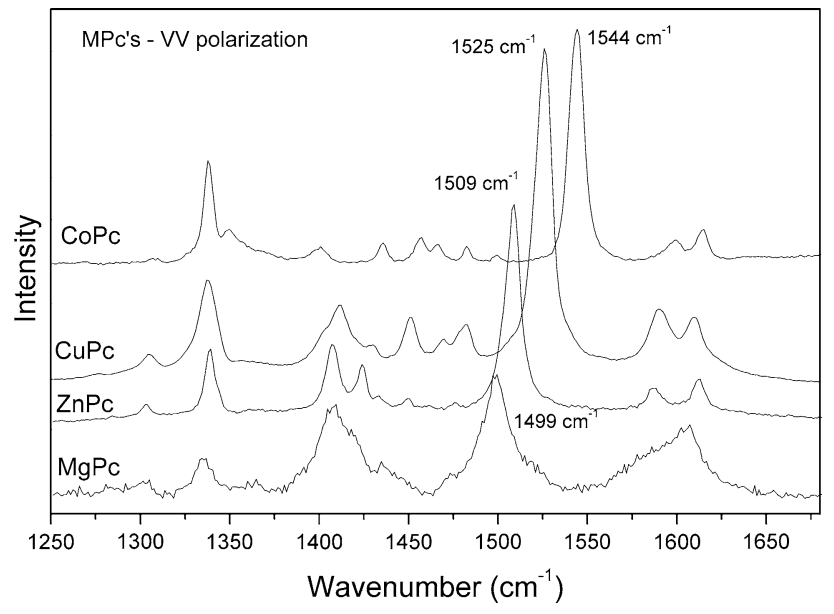

Fig. 2 The polarized (VV) Raman spectra of $\mathrm{CoPc}, \mathrm{CuPc}, \mathrm{ZnPc}$, and $\mathrm{MgPc}$ thin layer

from 1350 to $1550 \mathrm{~cm}^{-1}$. This region corresponds to heavy atom-nitrogen (M-nitrogen) in-plane stretching and bending vibrations as well as displacements on the $\mathrm{C}-\mathrm{N}-\mathrm{C}$ bridge bond of the phthalocyanine molecule. The change of position of pyrrole stretch band is presented in Fig. 2. As it can be seen from this figure, the position of this band changes from $1544 \mathrm{~cm}^{-1}$ for $\mathrm{CoPc}, 1525 \mathrm{~cm}^{-1}$ for $\mathrm{CuPc}$, $1509 \mathrm{~cm}^{-1}$ for $\mathrm{ZnPc}$ to $1499 \mathrm{~cm}^{-1}$ for MgPc thin layers. This vibration is characterized by the displacement of $\mathrm{C}-\mathrm{N}-\mathrm{C}$ bridge bonds of the phthalocyanine macrocycle. We have observed shift up to $45 \mathrm{~cm}^{-1}(5.58 \mathrm{meV})$ depending on the metal ion. This effect is probably caused by the metal ion size and cavity diameter of MPc.

Therefore, this band allows us for easy identification of adopted metal ion. Because this band is most intense in the Raman spectrum we have used it to determine the orientation of the investigated thin layers. Using integral intensity of this band obtained from polarized Raman spectra (VV and $\mathrm{VH}$ ), we can estimate the angle between molecule and substrate.

We have also performed surface Raman mapping (area $20 \times 20 \mu \mathrm{m}$ ) before and after annealing procedure in order to obtain information on distribution of polymorphic form of MPc thin layer. The annealing process was carried out in temperature cell at temperature equals to $200{ }^{\circ} \mathrm{C}$ by $6 \mathrm{~h}$. Raman mapping spectra were measured with the step of $2 \mu \mathrm{m}$. The full Raman map consisted of 121 Raman spectra. We have recorded two types of polarized Raman map for $\mathrm{VV}$ and $\mathrm{VH}$ polarization. Using numerical procedure, each spectrum was fitted to the theoretical Lorentz curve (using Wire 3.0 inVia software) to obtain integral intensity of $\mathrm{B}_{1 \mathrm{~g}}$ pyrrole stretch Raman mode. Using relation (1) and (2) for $I_{\mathrm{VV}}$ and $I_{\mathrm{VH}}$ intensity (described above) of Raman mode we have calculated the ratio intensities and then the angle between molecule and substrate. The same maps have been measured in the same area after the annealing process using the markers placed on the substrate. Using a microscope, it was possible to identify markers of the same investigated area.

Figure 3 presents maps of angle between molecule and substrate estimated from polarized Raman spectra for $\mathrm{ZnPc}$ thin layer deposited on silicon substrate before (a) and after annealing (b) procedure, respectively. In the case of the map obtained before annealing process (Fig. 3a), we observe the disordered surface with different orientation of the deposited $\mathrm{ZnPc}$ thin layer. The angle between molecule and substrate changes from $33^{\circ}$ to $49^{\circ}$. In the $\alpha$ - and $\beta$-form this angle is $25^{\circ}-35^{\circ}$ and $40^{\circ}-49^{\circ}$, respectively $[19,23]$. This proves that in the case of $\mathrm{ZnPc}$ thin layer there are two types of polymorphic phase: $\alpha$ and $\beta$ form, respectively. We also observed additional phase of $\mathrm{ZnPc}$ (angle between $36^{\circ}$ and $39^{\circ}$ ), which is between $\alpha$ and $\beta$ form. Figure $3 \mathrm{~b}$ shows the same map obtained after annealing process. As it can be seen from this figure, the annealing process $(6 \mathrm{~h}$ at $200{ }^{\circ} \mathrm{C}$ ) caused reorientation of the deposited molecules. We have observed in the investigated area the molecular arrangement caused by changes of the angle between molecules and substrate. The estimated angle changes from $39^{\circ}$ to $50^{\circ}$. This means that annealing process leads to existence only one of polymorphic form, namely stable $\beta$ form.

Figure 4 shows polarized Raman spectra for $\mathrm{ZnPc}$ thin layer recorded before and after annealing procedure. We observe the change of intensity ratio of pyrrole stretch band at $1509 \mathrm{~cm}^{-1}$ to macrocycle breathing vibration at $677 \mathrm{~cm}^{-1}$ before and after annealing process. Before annealing procedure the intensity ratio equals to 3.6 but after annealing process it decreases to 2.5. This effect is probably connected with the change of molecular structure of the $\mathrm{ZnPc}$ thin layer. This phenomenon was observed in the case of temperature measurements of $\mathrm{ZnPc}$ thin layer during phase transition from $\alpha$ to $\beta$ phase [17].

The same investigations and analysis were performed for $\mathrm{CuPc}, \mathrm{CoPc}$, and $\mathrm{MgPc}$ thin layers deposited on silicon substrate. Figures 5, 6, and 7 illustrate maps of angles between molecules and substrate obtained before and after annealing process for $\mathrm{CuPc}, \mathrm{CoPc}$, and $\mathrm{MgPc}$ thin layer, respectively. As it is seen in Fig. 5a, the orientation of $\mathrm{CuPc}$ molecules before annealing changes in the range from $35^{\circ}$ to $39^{\circ}$. It is intermediate phase between $\alpha$ and $\beta$ form. However, after annealing process (Fig. 5b) the angle increases and changes from $45^{\circ}$ to $47^{\circ}$.

We observed very well ordered structure of the almost homogeneous $\beta$ phase. Figure 6 shows maps obtained for $\mathrm{MgPc}$ thin layer. As it can be seen in Fig. 6a, we observe only metastable $\alpha$ form (angle $26^{\circ}-36^{\circ}$ ). However, annealing process causes phase transformation from $\alpha$ to $\beta$ form. After annealing procedure, the angle varies from $39^{\circ}$ 

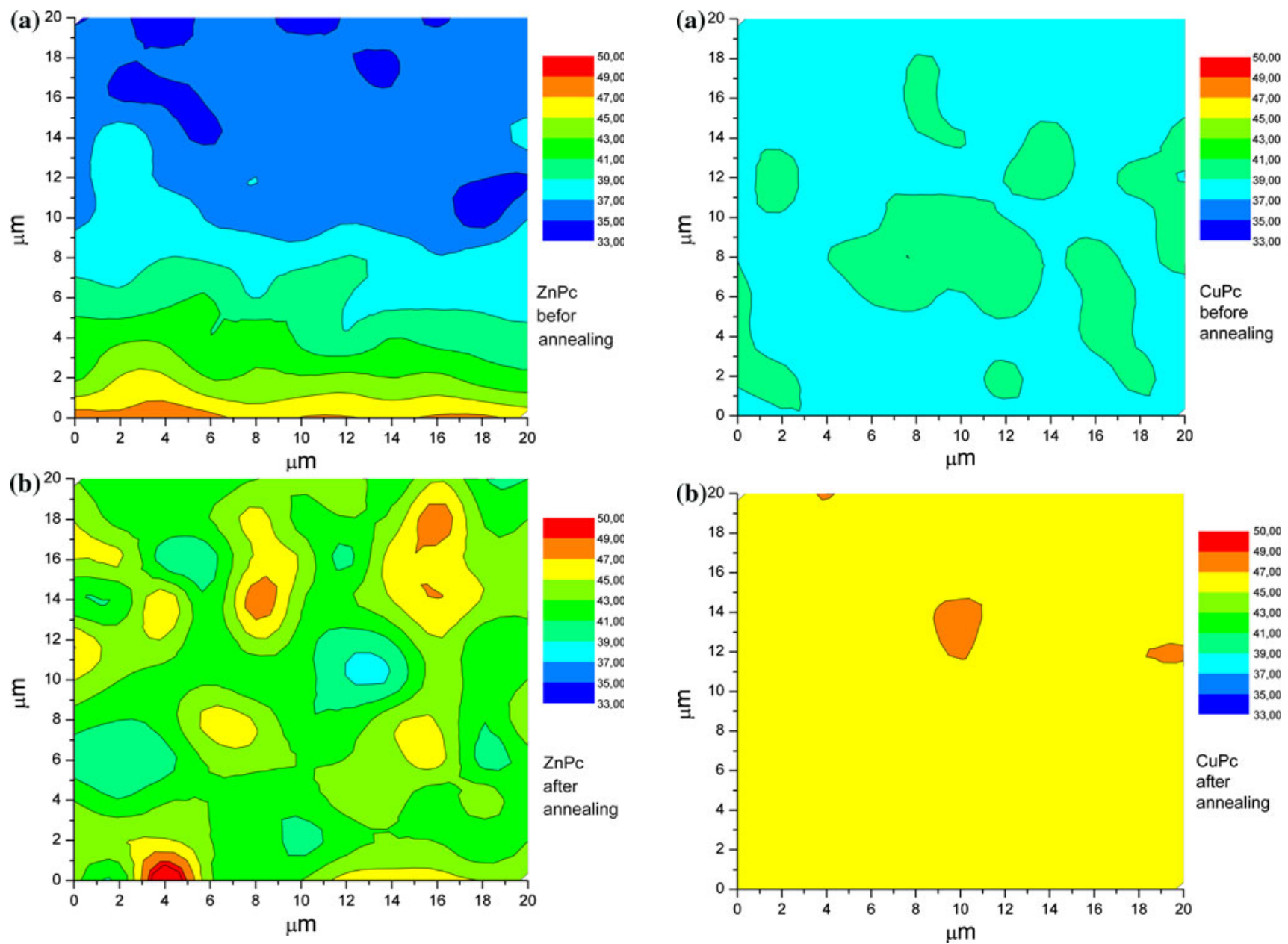

Fig. 3 Maps of angles between molecule $\mathrm{ZnPc}$ and substrate estimated from polarized Raman spectra: before (a) and after (b) annealing procedure

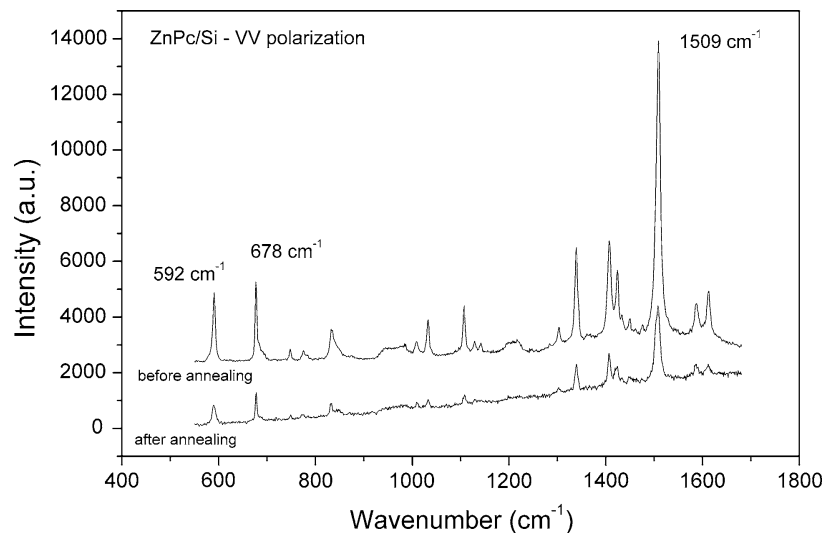

Fig. 4 The polarized (VV) Raman spectra of $\mathrm{ZnPc}$ thin layer obtained before and after annealing procedure

to $48^{\circ}$. We have observed in the whole investigated area the presence of one form- $\beta$. The best results we have obtained for annealed of CoPc thin layer deposited on silicon substrate (see Fig. 7). In this case, annealing

Fig. 5 Maps of angles between molecule CuPc and substrate estimated from polarized Raman spectra: before (a) and after (b) annealing procedure

process has causes total arrangement of CoPc thin layer and leads to homogeneous structure with angle between molecule and substrate equals to $48^{\circ}$ and homogeneous $\beta$ phase of cobalt phthalocyanine.

As it is seen from Figs. 3, 5, 6, and 7, the higher disorder of molecules is observed for $\mathrm{ZnPc}$ thin layer both, before and after annealing process. Admittedly, annealing process improves the structure of the thin layer, which possesses a homogeneous phase (phase transition from $\alpha$ to $\beta$ phase during annealing process) but does not show a high molecular arrangement. This is probably connected with the symmetry of deposited molecule.

According to the literature data and theoretical calculations using density functional theory method in the case of $\mathrm{ZnPc}$ molecule, we have observed the differences in symmetry of $\mathrm{ZnPc}$ and $\mathrm{CuPc}$ or $\mathrm{CoPc}$ molecules. Adoption of the copper and cobalt by phthalocyanine molecule creates the planar MPc molecule of symmetry $\mathrm{D}_{4 \mathrm{~h}}$. For CuPc and $\mathrm{CoPc}$ ionic diameter is smaller than the cavity diameter 

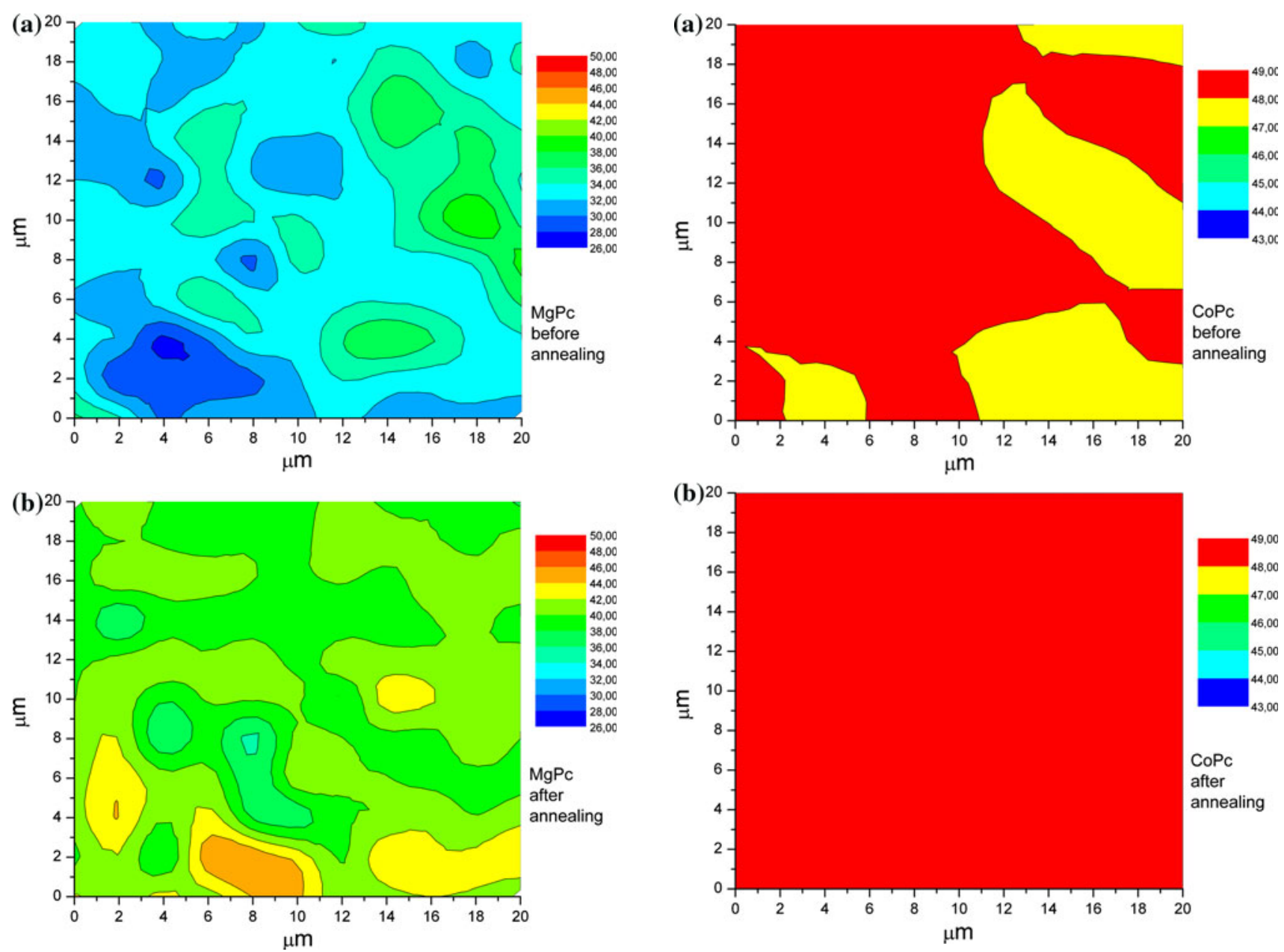

Fig. 6 Maps of angles between molecule MgPc and substrate estimated from polarized Raman spectra: before (a) and after (b) annealing procedure

of $\mathrm{H}_{2} \mathrm{Pc}$ molecule. In the case of $\mathrm{Zn}$ atom ionic diameter is higher than cavity diameter of $\mathrm{H}_{2} \mathrm{Pc}$ by about $0.075 \AA$. This means that we can observe nonplanarity of MPc for large metal ions $[24,25]$. Thus, for the $\mathrm{ZnPc}$ thin layer the molecular arrangement is more complicated assuming distortion of planarity with different symmetry of molecule than $\mathrm{D}_{4 \mathrm{~h}}$. In the previous studies, we have reported the change of symmetry of molecule in high temperature from $\mathrm{D}_{4 \mathrm{~h}}$ (planar molecule) to $\mathrm{C}_{4 \mathrm{v}}$ (distortion molecule) [26]. This transformation has an influence on the orientation of the organic thin layers. Moreover, it is connected with the increase of the average $\mathrm{M}-\mathrm{N}$ distance in the MPc molecule and thereby changes of planarity of the molecule (change of molecular symmetry).

In Fig. 8 we present average angle between molecule and silicon substrate for $\mathrm{ZnPc}, \mathrm{CuPc}, \mathrm{CoPc}$, and $\mathrm{MgPc}$ estimated both, before and after annealing procedure. In all cases, we observe increase of the angle between molecule and substrate and change of polymorphic phase caused by

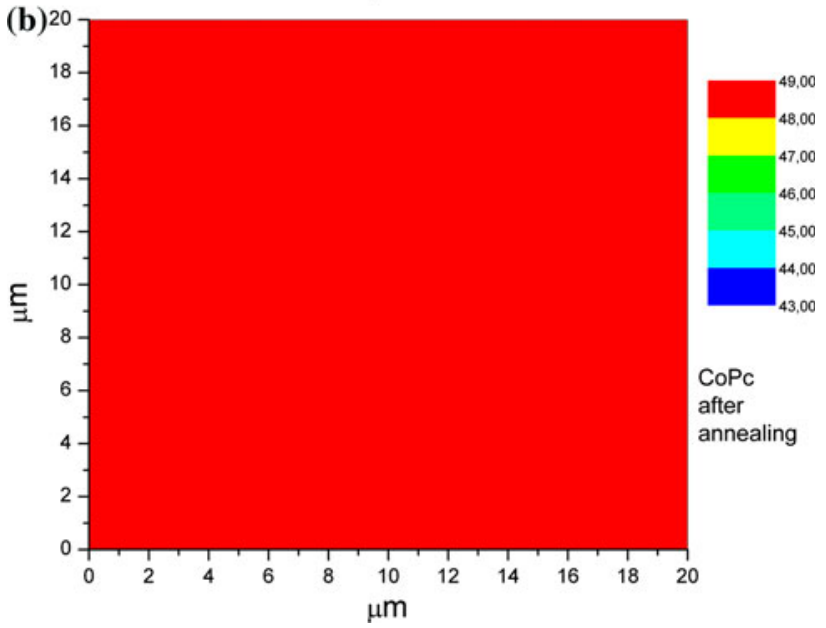

Fig. 7 Maps of angles between molecule $\mathrm{CoPc}$ and substrate estimated from polarized Raman spectra: before (a) and after (b) annealing procedure

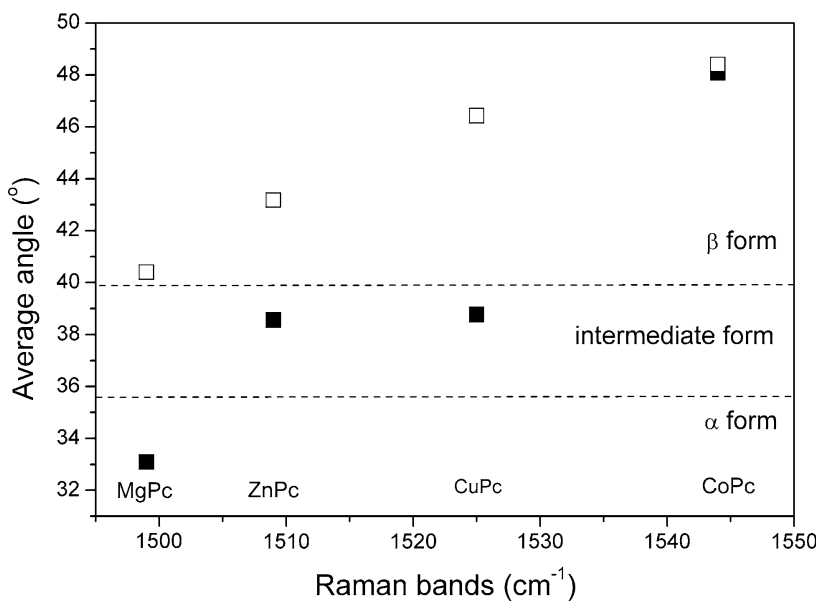

Fig. 8 Angle (average) between molecule MPc and substrate (filled square before annealing, open square after annealing)

annealing process. These results are in good agreement with results obtained by Tackley et al. in [24]. For CuPc and $\mathrm{CoPc}$ ionic diameter is smaller than cavity diameter of 
$\mathrm{H}_{2} \mathrm{Pc}$ molecule but for $\mathrm{Zn}$ atom ionic diameter is higher than cavity diameter of $\mathrm{H}_{2} \mathrm{Pc}$ causing the increase of the angle between substrate and plane of molecule. The layer annealed in higher temperature causes smaller difference in the angles between different phthalocyanines.

\section{Conclusions}

It has been revealed, that micro-Raman scattering spectroscopy is very useful to investigate molecular orientation of the $\mathrm{ZnPc}, \mathrm{CuPc}, \mathrm{CoPc}$, and $\mathrm{MgPc}$ thin layers deposited on solid state substrate.

In this article, we report orientation study of $\mathrm{ZnPc}$, $\mathrm{CuPc}, \mathrm{CoPc}$, and $\mathrm{MgPc}$ thin layers deposited on silicon substrate using micro-Raman scattering method. The polymorphic phase, temperature stability, symmetry of molecules, and preferred arrangement of MPc thin layer is closely related to the physical (optical and electrical) properties. The obtained results indicate a significant influence of the annealing process on the preferred molecular orientation and distribution of polymorphic phase of MPc thin film deposited on silicon substrate.

Acknowledgements This study was supported by the Research Projects of Poznan University of Technology: 64-001/2011-DS and Kazimierz Wielki University (Bydgoszcz): Research Project of Ministry of Science and Higher Education no. R05 004506.

Open Access This article is distributed under the terms of the Creative Commons Attribution Noncommercial License which permits any noncommercial use, distribution, and reproduction in any medium, provided the original author(s) and source are credited.

\section{References}

1. Jakubik WP (2009) Thin Solid Films 517:6188
2. Medina A, Claessens CG (2009) J Phorphyr Phthalocyanines $13: 446$

3. Pfuetzner S, Meiss J, Petrich A, Riede M, Leo K (2009) Appl Phys Lett 94:253303

4. Kato S, Moryiama H, Takahashi K, Pac C (2009) J Mater Chem 19:8403

5. Tang CW, Slyke SAV (1987) Appl Phys Lett 51:913

6. Simon J, Andre JJ (1985) Molecular semiconductors. SpringerVerlag, Berlin

7. Erk P (1997) In: Proceedings of the 17th Europen Crystallographic Meeting, AIP Press, Lisbon, 24-28 Aug 1997

8. Debe M, Poirier R, Kam K (1991) Thin Solid Films 197:335

9. Sharp JH, Abkowitz M (1973) J Phys Chem 77:477

10. Assour JM (1965) J Phys Chem 69:2295

11. Brożek-Płuska B, Jarota A, Kurczewski K, Abramczyk H (2009) J Mol Struct 338:924

12. Brożek-Płuska B, Szymczyk I, Abramczyk H (2005) J Mol Struct 481:744

13. Debe M, Kam K (1990) Thin Solid Films 186:289

14. Saijo H, Kobayashi T, Uyeda N (1977) J Crystal Growth 40:118

15. Berger O, Fisher WJ, Adolphi B, Tierbach S (2000) J Mat Sci Mater Electron 11:331

16. Zanfolim AZ, Volpati D, Olivati CA, Job AE, Constantino CJL (2010) J Phys Chem C 114:12290

17. Gaffo L, Cordeiro MR, Freitas AR, Moreira WC, Girotto EM, Zucolotto V (2010) J Mater Sci 45:1366. doi:10.1007/s10853009-4094-3

18. Louis JS, Lehmann D, Friedrich M, Zahn DRT (2007) J Appl Phys 101:013503

19. Kolesov BA, Basova TV (1997) Thin Solid Films 304:166

20. Basova TV, Kolesov BA (2000) J Struct Chem 41:770

21. Szybowicz M, Runka T, Drozdowski M, Bała W, Grodzicki A, Piszczek P, Bratkowski A (2004) J Mol Struct 704:107

22. Szybowicz M, Bała W, Fabisiak K, Paprocki K, Drozdowski M (2010) Cryst Res Technol 45(12):1265

23. Basova T, Kolesov B (1998) Thin Solid Films 325:140

24. Tackley DR, Dent G, Smith WE (2001) Phys Chem Chem Phys 3:1419

25. Liu Z, Zhang X, Zhang Y, Jiang J (2007) Spectrochimica Acta A 67:1232

26. Szybowicz M, Runka T, Drozdowski M, Bała W, Wojdyła M, Grodzicki A, Piszczek P, Bratkowski A (2007) J Mol Struct 830:14 